\title{
Forecasting Volatility of Gold Price Using Markov Regime Switching and Trading Strategy
}

\author{
Nop Sopipan ${ }^{1}$, Pairote Sattayatham ${ }^{1}$, Bhusana Premanode ${ }^{2}$ \\ ${ }^{1}$ School of Mathematics Suranaree, University of Technology, Nakhon Ratchasima, Thailand \\ ${ }^{2}$ Institute of Biomedical Engineering, Imperial College South Kensington Campus, London, UK \\ Email: \{nopsopipan, bhusana\}@gmail.com, pairote@sut.ac.th
}

Received October 24, 2011; revised December 1, 2011; accepted December 15, 2011

\begin{abstract}
In this paper, we forecast the volatility of gold prices using Markov Regime Switching GARCH (MRS-GARCH) models. These models allow volatility to have different dynamics according to unobserved regime variables. The main purpose of this paper is to find out whether MRS-GARCH models are an improvement on the GARCH type models in terms of modeling and forecasting gold price volatility. The MRS-GARCH is best performance model for gold price volatility in some loss function. Moreover, we forecast closing prices of gold price to trade future contract. MRSGARCH got the most cumulative return same GJR model.
\end{abstract}

Keywords: Forecasting; Volatility; Gold Price; Markov Regime Switching

\section{Introduction}

The characteristic that all financial markets have in common is uncertainty, which is related to their short and longterm price state. This feature is undesirable for the investor but it is also unavoidable whenever the financial market is selected as the investment tool. The best that one can do is to try to reduce this uncertainty. Financial market forecasting (or Prediction) is one of the instruments in this process.

The financial market forecasting task divides researchers and academics into two groups: those who believe that we can devise mechanisms to predict the market and those who believe that the market is efficient and whenever new information comes up the market absorbs it by correcting itself, thus there is no space for prediction. Furthermore they believe that the financial market follows a random walk, which implies that the best prediction you can have about tomorrow's value is today's value.

In time series, a financial price transformated to $\log$ return series for stationary process which look like white noise. Mehmet [1] said financial returns have three characteristics. First is volatility clustering that means large changes tend to be followed by large changes and small changes tend to be followed by small changes. Second is fat tailedness (excess kurtosis) which means that financial returns often display a fatter tail than a standard normal distribution and the third is leverage effect which means that negative returns result in higher volatility than positive returns of the same size.
The generalized autoregressive conditional heteroskedasticity (GARCH) models mainly capture three characteristics of financial returns. The development of GARCH type models was started by Engle [2]. Engle introduced ARCH to model the heteroskedasticity by relating the conditional variance of the disturbance term to the linear combination of the squared disturbances in the recent past. Bollerslev [3] generalized the ARCH (GARCH) model by modeling the conditional variance to depend on its lagged values as well as squared lagged values of disturbance. The Exponential GARCH (EGARCH) model proposed by Nelson [4] to cope with the skewness of ten encountered in financial returns, led to GJR-GARCH which was introduced independently by Glosten, Aganathan, and Runkle [5] to account for the leverage effect.

Hamilton and Susmel [6] stated that the spurious high persistence problem in GARCH type models can be solved by combining the Markov Regime Switching (MRS) model with ARCH models (SWARCH). The idea behind regime switching models is that as market conditions change, the factors that influence volatility also change. Nowaday some researchers have development of GARCH model, as well as the benefit of using GARCH model [1, 7-9].

Gold is a precious metal which is also classed as a commodity and a monetary asset. Gold has acted as a multifaceted metal through the centuries, possessing similar characteristics to money in that it acts as a store of wealth, a medium of exchange and a unit of value. Gold has also played an important role as a precious metal with sig- 
nificant portfolio diversification properties. Gold is used in industrial components, jewellery and as an investment asset. The quantity of gold required is determined by the quantity demanded for industry investment and jewellery use. Therefore an increase in the quantity demanded by the industry will lead to an increase in the price of the metal.

The changing price of gold can also be the result of a change in the Central Bank's holding of these precious metals. In addition, changes in the rate of inflation, currency markets, political harmony, equity markets, and producer and supplier hedging, all affect the price equilibrium.

Gold futures is an alternative investment tool which relies on the gold price movement. The investors can benefit from the gold futures investment by making profit from both directions, either up or down, which is like stock index futures trading. In addition, gold futures can also hedge against gold price fluctuations or stock market volatility due to the negative correlation to the stock market. This will provide a greater opportunity to make profit when the stock market declines during an economic downturn.

Gold futures in Thailand are futures contracts which rely on gold bullion with a purity of $96.5 \%$ due its popularity among buyers nationwide for gold physical trading. Gold futures trade in implement cash settlement method with no need of physical delivery.

Edel Tully, et al. [10] has investigated the Asymmmetric power GARCH model has to capture the dynamics of the gold market. Results suggest that the APGARCH model provides the most adequate description for the gold price.

In this paper, we use GARCH, EGARCH, GJR-GARCH and MRS-GARCH models to forecast the volatility of gold prices and to compare their performance. Moreover we shall use this estimated volatility to forecast the closing price of gold. Finally, we apply the forecasting price of gold to trading in gold future contracts with a maturity date of August 2011 (GF10Q11).

In the next section, we present the MRS-GARCH model. Estimation and in-sample evaluation results are given in Section 3. In Section 4, statistical loss functions are described and out-of-sample forecasting performance of various models is discussed. In Section 5 we apply the forecasting price to the gold price for trading in future contracts. The conclusion is given in Section 6.

\section{Markov Regime Switching of GARCH Model}

Let $\left\{P_{t}\right\}$ denote the series of the financial price at time $t$ and $\left\{r_{t}\right\}_{t>0}$ be a sequence of random variables on a probability space $(\Omega, F, \mathrm{P})$. For index $t$ denotes the daily closing observations and $t=-R+1, \cdots, n$. The sample period consists of an estimation (or in-sample) period with $R$ observations $(t=-R+1, \cdots, 0)$, and an evolution (or out-of-sample) period with $n$ observations $(t=1, \cdots, n)$, let $r_{t}$ be the logarithmic return (in percent) on the financial price at time $t$, i.e.

$$
r_{t}=100 \cdot \ln \left(\frac{P_{t}}{P_{t-1}}\right)
$$

The GARCH $(1,1)$ model for the series of the returns $r_{t}$ can be written as

$$
\begin{aligned}
& r_{t}=\delta+\varepsilon_{t}=\delta+\eta_{t} \sqrt{h_{t}} \\
& h_{t}=\alpha_{0}+\alpha_{1} \varepsilon_{t-1}^{2}+\beta_{1} h_{t-1}
\end{aligned}
$$

where $\alpha_{0}>0, \alpha_{1} \geq 0$ and $\beta_{1} \geq 0$ are assumed to be nonnegative real constants to ensure that $h_{t} \geq 0$. We assume $\eta_{t}$ is an i.i.d. process with zero mean and unit variance.

The parameters of the GARCH model are generally considered as constants. But the movement of financial returns between recession and expansion is different, and may result in differences in volatility. Gray [11] extended the GARCH model to the MRS-GARCH model in order to capture regime changes in volatility with unobservable state variables. It was assumed that those unobservable state variables satisfy the first order Markov Chain process.

The MRS-GARCH model with only two regimes can be represented as follows:

$$
r_{t}=\delta_{S_{t}}+\varepsilon_{t}=\delta_{S_{t}}+\eta_{t} \sqrt{h_{t, S_{t}}}
$$

and $h_{t, S_{t}}=\alpha_{0, S_{t}}+\alpha_{1, S_{t}} \varepsilon_{t-1}^{2}+\beta_{1, S_{t}} h_{t-1}$.

where $S_{t}=1$ or $2, \delta_{S_{t}}$ is the mean and $h_{t, S_{t}}$ is the volatility under regime $S_{t}$ on $F_{t-1}$, both are measureable functions of $F_{t-\tau}$ for $\tau \leq t-1$. In order to ensure easily the positive of conditional variance we impose the restrictions $\alpha_{0, S_{t}}>0, \alpha_{1, S_{t}} \geq 0$ and $\beta_{1, S_{t}} \geq 0$. The sum $\alpha_{1, S_{t}}+\beta_{1, S_{t}}$ measures the persistence of a shock to the conditional variance.

The unobserved regime variable $S_{t}$ is governed by a first order Markov Chain with constant transition probabilities given by

$$
\operatorname{Pr}\left(S_{t}=i \mid S_{t-1}=j\right)=p_{j i} \text { for } i, j=1,2
$$

In matrix notation,

$$
P=\left[\begin{array}{ll}
p_{11} & p_{21} \\
p_{12} & p_{22}
\end{array}\right]=\left[\begin{array}{cc}
p & 1-q \\
1-p & q
\end{array}\right]
$$

\subsection{Forecasting Volatility}

In MRS-GARCH model with two regimes, Klaassen [12] forecast volatility for $k$-step-ahead by using the recursive method as in the standard GARCH model where $k$ is a 
positive integer. In order to compute the multi-step-ahead volatility forecasts, we firstly compute a weighted average of the multi-step-ahead volatility forecasts in each regime where the weights are the prediction probability $\left(\operatorname{Pr}\left(S_{T+\tau}=i \mid F_{T-1}\right)\right)$.

Since there is no serial correlation in the returns, the $k$-step-ahead volatility forecast at time $T$ depends on information at time $T-1$. Let $\hat{h}_{T, T+k}$ denote the time $T$ aggregated volatility forecasts for the next $k$ steps. It can be calculated as follows: (See, for example Marcucci [9], page 8)

$$
\begin{aligned}
\hat{h}_{T, T+k} & =\sum_{\tau=1}^{k} \hat{h}_{T, T+\tau} \\
& =\sum_{\tau=1}^{k}\left[\sum_{i=1}^{2} \operatorname{Pr}\left(S_{T+\tau}=i \mid F_{T-1}\right) \hat{h}_{T, T+\tau, S_{T+\tau}=i}\right] .
\end{aligned}
$$

where $\hat{h}_{T, T+\tau, S_{T+\tau}=i}$ indicates the $\tau$-step-ahead volatileity forecast in regime $i$ made at time $T$ and can be calculated recursively as follows:

$$
\begin{aligned}
& \hat{h}_{T, T+\tau, S_{T+\tau}=i}=E_{T-1}\left(\hat{h}_{T+\tau-1} \mid S_{T+\tau}=i\right) \\
& =\alpha_{0, S_{T+\tau}=i}+\alpha_{1, S_{T+\tau}=i} E_{T-1}\left(\varepsilon_{T+\tau-1}^{2} \mid S_{T+\tau}=i\right) \\
& +\beta_{1, S_{T+\tau}=i} E_{T-1}\left(h_{T+\tau-1} \mid S_{T+\tau}=i\right) \\
& =\alpha_{0, S_{T+\tau}=i}+\alpha_{1, S_{T+\tau}=i} E_{T-1}\left(E_{T-1}\left[\varepsilon_{T+\tau-1}^{2} \mid S_{T+\tau-1}\right] \mid S_{T+\tau}=i\right) \\
& +\beta_{1, S_{T+\tau}=i} E_{T-1}\left(h_{T+\tau-1} \mid S_{T+\tau}=i\right) \\
& =\alpha_{0, S_{T+\tau}=i}+\left(\alpha_{1, S_{T+\tau}=i}+\beta_{1, S_{T+\tau}=i}\right) E_{T-1}\left(h_{T, T+\tau-1} \mid S_{T+\tau}=i\right) .
\end{aligned}
$$

Also, in generally the prediction probability in (5) is computed as

$$
\left[\begin{array}{l}
\operatorname{Pr}\left(S_{T+\tau}=1 \mid F_{T-1}\right) \\
\operatorname{Pr}\left(S_{T+\tau}=2 \mid F_{T-1}\right)
\end{array}\right]=P^{\tau+1} \cdot\left[\begin{array}{c}
\operatorname{Pr}\left(S_{T-1}=1 \mid F_{T-1}\right) \\
\operatorname{Pr}\left(S_{T-1}=2 \mid F_{T-1}\right)
\end{array}\right],
$$

where $P$ defined in (4) and $\operatorname{Pr}\left(S_{T-1}=i \mid F_{T-1}\right)$ will be discussed in (11). Lastly, we compute expectation part $E_{T-1}\left(h_{T, T+\tau-1} \mid S_{T+\tau}=i\right)$ in (6) as follows:

$$
\begin{aligned}
& E_{T-1}\left(h_{T, T+\tau-1} \mid S_{T+\tau}=i\right)=E\left[h_{T+\tau-1} \mid S_{T+\tau}=i, F_{T-1}\right] \\
&=E\left[E\left[r_{T+\tau-1}^{2} \mid S_{T+\tau-1}=j, F_{T-1}\right]\right. \\
&-\left.-\left[E\left[r_{T+\tau-1} \mid S_{T+\tau-1}=j, F_{T-1}\right]\right]^{2} \mid S_{T+\tau}=i, F_{T-1}\right] \\
&= E\left[E\left[r_{T+\tau-1}^{2} \mid S_{T+\tau-1}=j, F_{T-1}\right] \mid S_{T+\tau}=i, F_{T-1}\right] \\
&- E\left[\left[E\left[r_{T+\tau-1} \mid S_{T+\tau-1}=j, F_{T-1}\right]\right]^{2} \mid S_{T+\tau}=i, F_{T-1}\right]
\end{aligned}
$$

where

$$
\begin{aligned}
E & {\left[E\left[r_{T+\tau-1}^{2} \mid S_{T+\tau-1}=j, F_{T-1}\right] \mid S_{T+\tau}=i, F_{T-1}\right] } \\
= & \sum_{j=1}^{2}\left\{E\left[r_{T+\tau-1}^{2} \mid S_{T+\tau-1}=j, F_{T-1}\right]\right. \\
& \left.\left.\cdot \operatorname{Pr}\left[S_{T+\tau-1}=j \mid S_{T+\tau}=i, F_{T-1}\right]\right]\right\} \\
= & \sum_{j=1}^{2}\left\{E\left[\left(\delta_{T+\tau-1}+\varepsilon_{T+\tau-1}\right)^{2} \mid S_{T+\tau-1}=j, F_{T-1}\right]\right. \\
& \left.\cdot \operatorname{Pr}\left[S_{T+\tau-1}=j \mid S_{T+\tau}=i, F_{T-1}\right]\right\} \\
= & \sum_{j=1}^{2}\left\{E\left[\delta_{T+\tau-1}^{2}+2 \delta_{T+\tau-1} \varepsilon_{T+\tau-1}+\varepsilon_{T+\tau-1}^{2} \mid S_{T+\tau-1}=j, F_{T-1}\right]\right. \\
& \left.\cdot \operatorname{Pr}\left[S_{T+\tau-1}=j \mid S_{T+\tau}=i, F_{T-1}\right]\right\} \\
= & \sum_{j=1}^{2} \tilde{p}_{j i, T-1}\left[\delta_{T+\tau-1, S_{T+\tau-1}=j}^{2}+h_{T+\tau-1, S_{T+\tau-1}=j}\right]
\end{aligned}
$$

where

$$
\begin{aligned}
\tilde{p}_{j i, T-1} & =\operatorname{Pr}\left(S_{T+\tau-1}=j \mid S_{T+\tau}=i, F_{T-1}\right) \\
& =\frac{p_{j i} \operatorname{Pr}\left(S_{T+\tau-1}=j \mid F_{T-1}\right)}{\operatorname{Pr}\left(S_{T+\tau}=i \mid F_{T-1}\right)} .
\end{aligned}
$$

Similarly, we computed in the second term of right hand side in (7) such that

$$
\begin{aligned}
& E\left[\left[E\left[r_{T+\tau-1} \mid S_{T+\tau-1}=j, F_{T-1}\right]\right]^{2} \mid S_{T+\tau}=i, F_{T-1}\right] \\
& =\sum_{j=1}^{2} \tilde{p}_{j i, T-1}\left[\delta_{T+\tau-1, S_{T+\tau-1}=j}\right]^{2}
\end{aligned}
$$

substitutes both (8) and (10) to (7) such that

$$
\begin{aligned}
& E_{T-1}\left(\hat{h}_{T, T+\tau-1} \mid S_{T+\tau}=i\right) \\
& =\sum_{j=1}^{2} \tilde{p}_{j i, T-1}\left[\delta_{T+\tau-1, S_{T+\tau-1}=j}^{2}+h_{T+\tau-1, S_{T+\tau-1}=j}\right] \\
& -\sum_{j=1}^{2} \tilde{p}_{j i, T-1}\left[\delta_{T+\tau-1, S_{T+\tau-1}=j}\right]^{2} .
\end{aligned}
$$

In the next step, we will compute those regime probabilities $p_{i t}=\operatorname{Pr}\left(S_{t}=i \mid F_{t-1}\right)$ for $i=1,2$ in (9). Note that when the regime probabilities are based on information up to time $t$, we describe this as filtered probability $\left(\operatorname{Pr}\left(S_{t}=i \mid F_{t}\right)\right)$.

In order to compute the regime probabilities, we denote $f_{1 t}:=f\left(r_{t} \mid S_{t}=1, F_{t-1}\right), \quad f_{2 t}:=f\left(r_{t} \mid S_{t}=2, F_{t-1}\right)$. Then, conditional distribution of return series $r_{t}$ becomes a mixture-of-distribution model in which mixing variables is regime probability $p_{i t}$. That is $r_{t} \mid F_{t-1} \sim\left\{\begin{array}{l}f\left(r_{t} \mid S_{t}=1, F_{t-1}\right) \quad \text { with probability } p_{1 t} \\ f\left(r_{t} \mid S_{t}=2, F_{t-1}\right) \quad \text { with probability } p_{2 t}=1-p_{1 t},\end{array}\right.$ where $f\left(r_{t} \mid S_{t}, F_{t-1}\right)$ denotes one of the assumed condi- 
tional distributions for errors: Normal Distribution $(\mathrm{N})$, Student-t Distribution with only single degree of freedom $(\mathrm{t})$ or double degree of freedom $(2 \mathrm{t})$ and Generalized error distributions (GED).

We shall compute regime probabilities recursively by following two steps (Kim and Nelson, [13], page 63):

Step 1: Given $\operatorname{Pr}\left(S_{t-1}=j \mid F_{t-1}\right)$ at the end of the time $t-1$, the regime probabilities $p_{i t}=\operatorname{Pr}\left(S_{t}=i \mid F_{t-1}\right)$ are computed as

$$
\operatorname{Pr}\left(S_{t}=i \mid F_{t-1}\right)=\sum_{j=1}^{2} \operatorname{Pr}\left(S_{t}=i, S_{t-1}=j \mid F_{t-1}\right) .
$$

Since the current regime $\left(S_{t}\right)$ only depends on the regime one period ago $\left(S_{t-1}\right)$, then

$$
\begin{aligned}
& \operatorname{Pr}\left(S_{t}=i \mid F_{t-1}\right) \\
& =\sum_{j=1}^{2} \operatorname{Pr}\left(S_{t}=i \mid S_{t-1}=j\right) \operatorname{Pr}\left(S_{t-1}=j \mid F_{t-1}\right) . \\
& =\sum_{j=1}^{2} p_{j i} \operatorname{Pr}\left(S_{t-1}=j \mid F_{t-1}\right)
\end{aligned}
$$

Step 2: At the end of the time $t$, when observed return at time $t\left(r_{t}\right)$ the information at time $t$ set $F_{t}=\left\{F_{t-1}, r_{t}\right\}$, the $\operatorname{Pr}\left(S_{t}=i \mid F_{t}\right)$ is calculated as follows:

$$
\operatorname{Pr}\left(S_{t}=i \mid F_{t}\right)=\operatorname{Pr}\left(S_{t}=i \mid r_{t}, F_{t-1}\right)=\frac{f\left(r_{t}, S_{t}=i \mid F_{t-1}\right)}{f\left(r_{t} \mid F_{t-1}\right)},
$$

where $f\left(r_{t}, S_{t}=i \mid F_{t-1}\right)$ is joint density of returns and unobserved regime at state $i$ for $i=1,2$ variables can be written as follows:

$$
\begin{aligned}
f\left(r_{t}, S_{t}=i \mid F_{t-1}\right) & =f\left(r_{t} \mid S_{t}=i, F_{t-1}\right) f\left(S_{t}=i \mid F_{t-1}\right) \\
& =f\left(r_{t} \mid S_{t}=i, F_{t-1}\right) \operatorname{Pr}\left(S_{t}=i \mid F_{t-1}\right)
\end{aligned}
$$

and $f\left(r_{t} \mid F_{t-1}\right)$ is marginal density function of returns can be constructed as follows:

$$
\begin{aligned}
f\left(r_{t} \mid F_{t-1}\right) & =\sum_{i=1}^{2} f\left(r_{t}, S_{t}=i \mid F_{t-1}\right) \\
& =\sum_{i=1}^{2} f\left(r_{t} \mid S_{t}=i, F_{t-1}\right) \operatorname{Pr}\left(S_{t}=i \mid F_{t-1}\right) .
\end{aligned}
$$

We use Bayesian arguments

$$
\begin{aligned}
\operatorname{Pr}\left(S_{t}=i \mid F_{t}\right) & =\frac{f\left(r_{t}, S_{t}=i \mid F_{t-1}\right)}{f\left(r_{t} \mid F_{t-1}\right)} \\
& =\frac{f\left(r_{t} \mid S_{t}=i, F_{t-1}\right) \operatorname{Pr}\left(S_{t}=i \mid F_{t-1}\right)}{\sum_{i=1}^{2} f\left(r_{t} \mid S_{t}=i, F_{t-1}\right) \operatorname{Pr}\left(S_{t}=i \mid F_{t-1}\right)} \\
= & \frac{f_{i t} p_{i t}}{\sum_{i=1}^{2} f_{i t} p_{i t}} .
\end{aligned}
$$

Then, all regime probabilities $p_{i t}$ can be computed by iterating these two steps. However, at the beginning of iteration $\operatorname{Pr}\left(S_{0}=i \mid F_{0}\right)$ for $i=1,2$ are necessary to start iteration. Hamilton $([14,15])$ suggest we should use unconditional regime probabilities instead of $\operatorname{Pr}\left(S_{0}=i \mid F_{0}\right)$. These are given by

$$
\begin{aligned}
& \pi_{1}=\operatorname{Pr}\left(S_{0}=1 \mid F_{0}\right)=\frac{1-q}{2-p-q}, \\
& \pi_{2}=\operatorname{Pr}\left(S_{0}=2 \mid F_{0}\right)=\frac{1-p}{2-p-q}
\end{aligned}
$$

Given initial values for regime probabilities, conditional mean and conditional variance in each regime, the parameters of the MRS-GARCH model can be obtained by maximizing numerically the log-likelihood function. The log-likelihood function is constructed recursively similar to that in GARCH models

\subsection{Forecasting Price}

We forecast financial price at $k$-step-ahead with MRSGARCH models. Denote $\hat{r}_{t, t+k}$ is $k$-step-ahead forecasting logarithm return of financial price at time $t$ depend on $F_{t-1}$.

We compute as:

$$
\hat{r}_{t, t+k}=E_{t-1}\left[r_{t+k}\right]=\sum_{i=1}^{2} \operatorname{Pr}\left(S_{t+k}=i \mid F_{t-1}\right) \cdot \hat{r}_{t, t+k, S_{t+k}=i}
$$

where

$$
\begin{aligned}
\hat{r}_{t, t+k, S_{t+k}=i} & =E_{t-1}\left[r_{t+k} \mid S_{t+k}=i\right] \\
& =E_{t-1}\left[\delta+\varepsilon_{t+k} \mid S_{t+k}=i\right] \\
& =E_{t-1}\left[\delta \mid S_{t+k}=i\right]+E_{t-1}\left[\varepsilon_{t+k} \mid S_{t+k}=i\right] \\
& =\sum_{j=1}^{2} \operatorname{Pr}\left(S_{t+k-1}=j \mid S_{t+k}=i, F_{t-1}\right) \cdot \delta_{S_{t+k}=i} \\
& =\sum_{j=1}^{2} \tilde{p}_{j i, t-1} \cdot \delta_{S_{t+k}=i}
\end{aligned}
$$

Forecasting financial price one-step-ahead, we use (12) and (1) combine in log-return of financial price is

$$
\hat{P}_{t+1}=P_{t} \cdot \exp \left[\frac{\sum_{i=1}^{2} \operatorname{Pr}\left(S_{t+1}=i \mid F_{t-1}\right) \cdot \sum_{j=1}^{2} \tilde{p}_{j i, t-1} \cdot \delta_{S_{t+1}=i}}{100}\right] \text {. }
$$

\section{Empirical Methodology and Model Estimation Results}

\subsection{Data}

The data set used in this study is the daily closed prices of gold price $\left(P_{t}\right)$ over the period 4/01/2007 through 
$31 / 08 / 2011$ ( $t=1, \cdots, 1213$ observations). The data set is obtained from the basis of the London Gold Market Fixing Limited on day and the foreign exchange rate for Baht to US dollars announced by TFEX (The Thailand Futures Exchange) on day, after conversion for weight and fineness. The data set is divided into in-sample $(R=$ 1192 observations) and out-of-sample ( $n=21$ observations). The plot of $P_{t}$ and $\log$ returns series $\left(r_{t} ;(1)\right)$ are given in Figure 1. Plot $P_{t}$ and $r_{t}$ displays usual properties of financial data series. As expected, volatility is not constant over time and exhibits volatility clustering with large changes in the indices often followed by large changes, and small changes often followed by small changes.

Descriptive statistics of $r_{t}$ are represented in Table 1. As Table 1 shows, $r_{t}$ has a positive average return of $0.074 \%$. The daily standard deviation is $1.537 \%$. The series also displays a negative skewness of -0.102 and an excess kurtosis of 9.457 . These values indicate that the returns are not normally distributed, namely it has fatter tails because skewness does not equal zero and kurtosis is greater than 3. Also, the Jarque-Bera test ${ }^{1}$ statistic of 2107.620 confirms the non-normality of $r_{t}$. And the

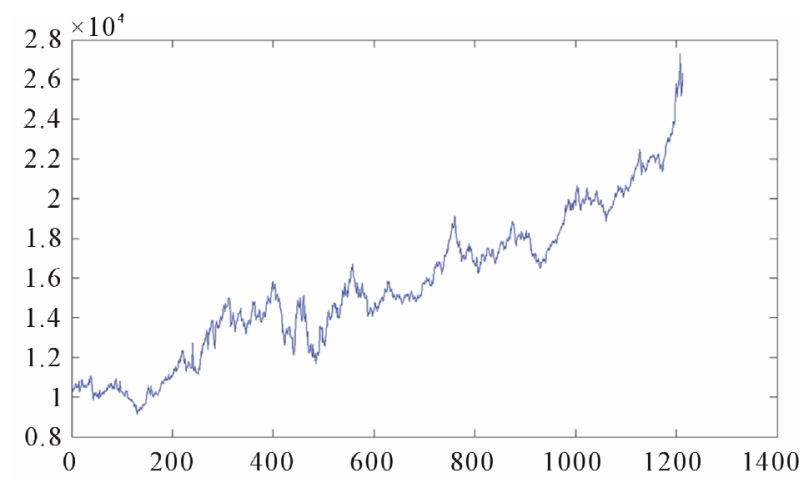

(a)

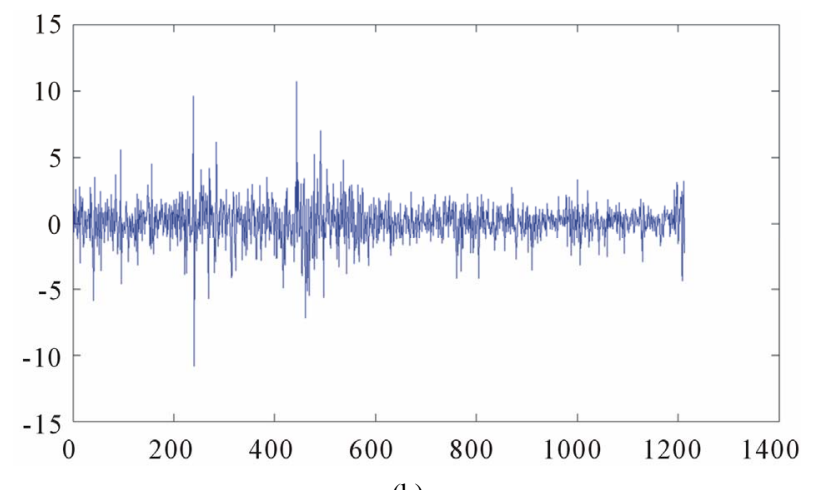

(b)

Figure 1. Graph of (a) Gold price closed prices $\left(P_{t}\right)$ and (b) $\log$ returns series $\left(r_{t}\right)$ for the period $4 / 01 / 2007$ through 30 / 08/2011.

${ }^{1}$ Jarque-Bera Normality test is a goodness-of-fit measure of departure from normality and can be used to test the null hypothesis that the data are from a normal distribution.
Augmented Dickey-Fuller test ${ }^{2}$ of -35.873 indicates that $r_{t}$ is stationary.

The autocorrelation functions (ACF) test the significance level of autocorrelation in Table 2, when we apply Ljung and Box Q-test. The null hypothesis of the test is that there is no serial correlation in the return series up to the specified lag. Serial correlation in the $P_{t}$ is confirmed as non-stationary but $r_{t}$ is stationary. Because the serial correlation in the squared returns is non-stationary this suggests conditional heteroskedasticity. Therefore, we analyze the significance of autocorrelation in the squared mean adjusted return $\left(r_{t}-\delta\right)^{2}$ series by Ljung-Box Qtest $^{3}$. And apply Engle's ARCH test ${ }^{4}$.

\subsection{Empirical Methodology}

This empirical part adopts GARCH type and MRSGARCH $(1,1)$ models to estimate the volatility of the $P_{t}$. GARCH type models that will be considered as GARCH $(1,1), \operatorname{EGARCH}(1,1)$ and GJR-GARCH $(1,1)$. In order to account for the fat tails feature of financial returns, we consider three different distributions for the innovations: Normal (N), Student-t (t) and Generalized Error Distributions (GED).

\subsubsection{GARCH Type Models}

Table 3 presents an estimation of the results for GARCH type models. It is clear from the table that almost all parameter estimates including $\delta$ in GARCH type models are highly significant at $1 \%$. However, the asymmetry effect term $\xi$ in EGARCH models is significantly dif-

Table 1. Summary statistics of Gold price log returns series $\left(r_{t}\right)$.

\begin{tabular}{cc}
\hline Statistic & Return $(\%)$ \\
\hline Min & -10.823 \\
Max & 10.71 \\
Mean & 0.074 \\
Standard deviation & 1.537 \\
Skewness & -0.102 \\
Kurtosis & 9.457 \\
Bera Normality test & $2107.620(P$-value $=0.000)$ \\
Jarque-Bgmented Dickey-Fuller test & $-35.873(P$-value $=0.000)$ \\
\hline
\end{tabular}

$\overline{{ }^{2} \text { Augmented Dickey-Fuller test is a test for a unit root in a time series }}$ sample, the null hypothesis of ADF test is that the series is nonstationary.

${ }^{3}$ Ljung-Box Q-test is a type of statistical test of whether any of a group of autocorrelations of a time series are different from zero.

${ }^{4} \mathrm{ARCH}$ test is test with null hypothesis that, in the absence of $\mathrm{ARCH}$ components, we have $\alpha_{i}=0$ for all $i=1,2, \cdots, q$. The alternative hypothesis is that, in the presence of ARCH components, at least one of the estimated $\alpha_{i}$ coefficients must be significant. 
Table 2. ACF of gold price closed price $\left(P_{t}\right)$, log returns series $\left(r_{t}\right)$, square return and results for Engle's ARCH Test.

\begin{tabular}{|c|c|c|c|c|c|c|c|c|c|c|c|}
\hline \multirow{2}{*}{ Lags } & \multicolumn{3}{|c|}{ ACF of Gold price closed price. } & \multicolumn{3}{|c|}{ ACF of Gold price log return. } & \multicolumn{3}{|c|}{ ACF of Gold price square return. } & \multicolumn{2}{|c|}{ Results for Engle's ARCH tes } \\
\hline & $\mathrm{ACF}$ & LBQ Test & $P$-value & $\mathrm{ACF}$ & LBQ Test & $P$-value & $\mathrm{ACF}$ & LBQ Test & $P$-value & ARCH Test & $P$-value \\
\hline 1 & 0.994 & 1202.126 & 0.000 & -0.035 & 1.473 & 0.225 & 0.236 & 67.585 & 0.000 & 67.675 & 0.000 \\
\hline 2 & 0.988 & 2391.372 & 0.000 & 0.057 & 5.370 & 0.068 & 0.049 & 70.550 & 0.000 & 67.735 & 0.000 \\
\hline 3 & 0.982 & 3567.530 & 0.000 & 0.006 & 5.410 & 0.144 & 0.050 & 73.579 & 0.000 & 69.796 & 0.000 \\
\hline 4 & 0.977 & 4732.067 & 0.000 & 0.028 & 6.336 & 0.175 & 0.047 & 76.324 & 0.000 & 70.644 & 0.000 \\
\hline 5 & 0.972 & 5885.596 & 0.000 & 0.022 & 6.948 & 0.225 & 0.029 & 77.340 & 0.000 & 70.695 & 0.000 \\
\hline 6 & 0.966 & 7026.176 & 0.000 & -0.062 & 11.578 & 0.072 & 0.074 & 83.996 & 0.000 & 75.784 & 0.000 \\
\hline 7 & 0.960 & 8152.993 & 0.000 & -0.023 & 12.206 & 0.094 & 0.022 & 84.561 & 0.000 & 76.115 & 0.000 \\
\hline 8 & 0.954 & 9267.290 & 0.000 & 0.070 & 18.159 & 0.020 & 0.045 & 87.058 & 0.000 & 78.019 & 0.000 \\
\hline 9 & 0.948 & 10368.939 & 0.000 & -0.024 & 18.893 & 0.026 & 0.050 & 90.053 & 0.000 & 78.693 & 0.000 \\
\hline 10 & 0.943 & 11458.607 & 0.000 & 0.010 & 19.025 & 0.040 & 0.006 & 90.102 & 0.000 & 79.005 & 0.000 \\
\hline 22 & 0.885 & 23713.861 & 0.000 & -0.046 & 34.412 & 0.045 & 0.056 & 178.444 & 0.000 & 126.931 & 0.000 \\
\hline
\end{tabular}

Table 3. Summary results of GARCH type models.

\begin{tabular}{|c|c|c|c|c|c|c|c|c|c|}
\hline \multirow{2}{*}{ Parameter } & \multicolumn{3}{|c|}{ GARCH } & \multicolumn{3}{|c|}{ EGARCH $^{5}$} & \multicolumn{3}{|c|}{ GJR-GARCH $^{6}$} \\
\hline & $\mathrm{N}$ & $\mathrm{t}$ & GED & $\mathrm{N}$ & $\mathrm{t}$ & GED & $\mathrm{N}$ & $\mathrm{t}$ & GED \\
\hline$\delta$ & $0.1012 * * *$ & $0.1229 * * *$ & $0.1164 * * *$ & $0.1341 * * *$ & $0.1367 * * *$ & $0.1308^{* * *}$ & $0.1083^{* * *}$ & $0.1259 * * *$ & $0.1191 * * *$ \\
\hline Std.err. & 0.0347 & 0.0336 & 0.0315 & 0.0358 & 0.0337 & 0.0320 & 0.0368 & 0.0338 & 0.0318 \\
\hline$\alpha_{0}$ & $0.0567 * * *$ & $0.0686^{* * *}$ & $0.0629 * * *$ & $-0.0974 * * *$ & $-0.0725 * * *$ & $-0.0844 * * *$ & $0.0546^{* * *}$ & $0.0640 * * *$ & $0.0598 * * *$ \\
\hline Std.err. & 0.0099 & 0.0174 & 0.0165 & 0.0099 & 0.0178 & 0.0178 & 0.0097 & 0.0159 & 0.0156 \\
\hline$\alpha_{1}$ & $0.0818^{* * *}$ & $0.0757 * * *$ & $0.0779 * * *$ & $0.1429 * * *$ & $0.1092 * * *$ & $0.1240^{* * *}$ & $0.0611 * * *$ & $0.0558 * * *$ & $0.0583 * * *$ \\
\hline Std.err. & 0.0088 & 0.0177 & 0.0168 & 0.0136 & 0.0255 & 0.0249 & 0.0123 & 0.0197 & 0.0206 \\
\hline$\beta_{1}$ & $0.8906 * * *$ & $0.8897 * * *$ & $0.8893 * * *$ & $0.0459 * * *$ & $0.0491 * * *$ & $0.0461 * * *$ & $0.8939 * * *$ & $0.8946^{* * *}$ & $0.8934 * * *$ \\
\hline Std.err. & 0.0091 & 0.0184 & 0.0175 & 0.0106 & 0.0172 & 0.0172 & 0.0092 & 0.0176 & 0.0172 \\
\hline$\xi$ & & & & $0.7175 * * *$ & $0.4317 * * *$ & $0.6245^{* * *}$ & $0.0993 * * *$ & $0.0914 * * *$ & $0.0941 * * *$ \\
\hline Std.err. & & & & 0.0040 & 0.0053 & 0.0059 & 0.0134 & 0.0252 & 0.0242 \\
\hline$v$ & & $5.1878 * * *$ & $1.2350 * * *$ & & $5.4135 * * *$ & $1.2694 * * *$ & & $5.2868 * * *$ & $1.2408 * * *$ \\
\hline Std.err. & & 0.7608 & 0.0534 & & 0.8081 & 0.0568 & & 0.7766 & 0.0530 \\
\hline $\log (\mathrm{L})$ & -2087.32 & -2033.89 & -2038.22 & -2370.03 & -2160.38 & -2185.16 & -2086.68 & -2033.63 & -2037.92 \\
\hline Persistence & 0.9724 & 0.9654 & 0.9672 & 0.0459 & 0.0491 & 0.0461 & 0.9741 & 0.9682 & 0.9696 \\
\hline \multirow[t]{2}{*}{ LBQ(22) } & 32.6362 & 32.6362 & 32.6362 & 32.6362 & 32.6362 & 32.6362 & 32.6362 & 32.6362 & 32.6362 \\
\hline & $(0.0672)$ & $(0.0672)$ & $(0.0672)$ & $(0.0672)$ & $(0.0672)$ & $(0.0672)$ & $(0.0672)$ & $(0.0672)$ & $(0.0672)$ \\
\hline \multirow[t]{2}{*}{$\mathrm{LBQ}^{2}(22)$} & 189.92 & 190.07 & 189.83 & 189.68 & 189.66 & 189.72 & 189.88 & 189.76 & 189.81 \\
\hline & $(0.0000)$ & $(0.0000)$ & $(0.0000)$ & $(0.0000)$ & $(0.0000)$ & $(0.0000)$ & $(0.0000)$ & $(0.0000)$ & $(0.0000)$ \\
\hline
\end{tabular}

$* * *$ and $* *$ refer the significance at $99 \%$ and $95 \%$ confidence level respectively, $\mathrm{LBQ}(22)$ is Ljung-Box test of innovation at lag $22, \mathrm{LBQ}^{2}(22)$ is $\mathrm{Ljung} \mathrm{B}$ of squared innovation at lag 22 and $P$-value for LBQ test in parentheses. Std.err is standard error.

${ }^{5}$ Model of $\operatorname{EGARCH}(1,1)$ is $\ln \left(h_{t}\right)=\alpha_{0}+\alpha_{1}\left|\frac{\varepsilon_{t-1}}{\sqrt{h_{t-1}}}\right|+\beta_{1} \ln \left(h_{t-1}\right)+\xi \frac{\varepsilon_{t-1}}{\sqrt{h_{t-1}}}$ where $\xi$ is the asymmetry parameter to capture leverage effect.

${ }^{6}$ Model of GJR-GARCH(1,1) is $h_{t}=\alpha_{0}+\alpha_{1} \varepsilon_{t-1}^{2}\left(1-I_{\left\{\varepsilon_{t-1}>0\right\}}\right)+\beta_{1} h_{t-1}+\xi \varepsilon_{t-1}^{2}\left(I_{\left\{\varepsilon_{t-1}>0\right\}}\right)$ where $I_{\left\{\varepsilon_{t-1}>0\right\}}$ is equal to one when $\varepsilon_{t-1}$ is greater than zero and another is zero. 
ferent from zero, which indicates unexpected negative returns implying higher conditional variance as compared to same size positive returns. All models display strong persistence in volatility ranging from 0.9654 to 0.9741 unless EGARCH models are very low, that is, volatility is likely to remain high over several price periods once it increases.

\subsubsection{Markov Regime Switching GARCH Models} Estimation results and summary statistics of MRS-GARCH models are presented in Table 4. Most parameter esti- mates in MRS-GARCH are significantly different from zero at least at $95 \%$ confidence level. But $\alpha_{0}$ and $\beta_{1}$ are insignificant in some states. All models display strong persistence in volatility, that is, volatility is likely to remain high over several price periods once it increases.

\subsubsection{In-Sample Evaluation}

We use various goodness-of-fit statistics to compare volatility models. These statistics are Akaike Information Criteria (AIC) Schwarz Bayesian Information Criteria (SBIC) and Log-likelihood (LOGL) values. In Table 5,

Table 4. Summary results of MRS-GARCH models.

\begin{tabular}{|c|c|c|c|c|c|c|c|c|}
\hline \multirow{3}{*}{$\begin{array}{c}\text { Parameters } \\
\text { State } i\end{array}$} & \multicolumn{8}{|c|}{ MRS-GARCH } \\
\hline & \multicolumn{2}{|c|}{$\mathrm{N}$} & \multicolumn{2}{|c|}{$\mathrm{t}$} & \multicolumn{2}{|c|}{$2 \mathrm{t}$} & \multicolumn{2}{|c|}{ GED } \\
\hline & $\begin{array}{l}\text { Low volatility } \\
\text { regime }\end{array}$ & $\begin{array}{l}\text { High volatility } \\
\text { regime }\end{array}$ & $\begin{array}{l}\text { Low volatility } \\
\text { regime }\end{array}$ & $\begin{array}{l}\text { High volatility } \\
\text { regime }\end{array}$ & $\begin{array}{l}\text { Low volatility } \\
\text { regime }\end{array}$ & $\begin{array}{l}\text { High volatility } \\
\text { regime }\end{array}$ & $\begin{array}{l}\text { Low volatility } \\
\text { regime }\end{array}$ & $\begin{array}{l}\text { High volatility } \\
\text { regime }\end{array}$ \\
\hline$\delta^{(i)}$ & $0.0830 * *$ & $0.1800 * *$ & $0.1136 * * *$ & $0.1699 * *$ & $0.1135^{* * *}$ & $0.1699 * *$ & $0.1708^{* *}$ & $0.1088 * * *$ \\
\hline Std.err. & 0.0404 & 0.0934 & 0.0388 & 0.0766 & 0.0389 & 0.0766 & 0.0776 & 0.0369 \\
\hline$\alpha_{0}^{(i)}$ & $0.0137^{*}$ & $2.1786^{* * *}$ & 0.0111 & $1.6163^{* * *}$ & 0.0111 & $1.6152 * * *$ & $1.8421 * * *$ & 0.0126 \\
\hline Std.err. & 0.0075 & 0.3353 & 0.0086 & 0.513 & 0.0086 & 0.531 & 0.487 & 0.0096 \\
\hline$\alpha_{1}^{(i)}$ & $0.0463 * * *$ & $0.3654 * * *$ & $0.0380 * *$ & $0.3170 * * *$ & $0.0380 * *$ & $0.3170 * * *$ & $0.3244 * * *$ & $0.0418^{* *}$ \\
\hline Std.err. & 0.0127 & 0.1029 & 0.016 & 0.1154 & 0.0161 & 0.1167 & 0.1258 & 0.018 \\
\hline$\beta_{1}^{(i)}$ & $0.9436 * * *$ & 0 & $0.9535 * * *$ & 0.1844 & $0.9535^{* * *}$ & 0.1859 & 0.1015 & $0.9485^{* * *}$ \\
\hline Std.err. & 0.0151 & 0.1115 & 0.0175 & 0.1771 & 0.0175 & 0.1798 & 0.1403 & 0.02 \\
\hline$p$ & \multicolumn{2}{|c|}{$0.9975 * * *$} & \multicolumn{2}{|c|}{$0.9981 * * *$} & \multicolumn{2}{|c|}{$0.9983 * * *$} & \multicolumn{2}{|c|}{$0.9981 * * *$} \\
\hline Std.err. & \multicolumn{2}{|c|}{0.0023} & \multicolumn{2}{|c|}{0.0024} & \multicolumn{2}{|c|}{0.0024} & \multicolumn{2}{|c|}{0.0029} \\
\hline$q$ & \multicolumn{2}{|c|}{$0.9976 * * *$} & \multicolumn{2}{|c|}{$0.9983 * * *$} & \multicolumn{2}{|c|}{$0.9981 * * *$} & \multicolumn{2}{|c|}{$0.9983^{* * *}$} \\
\hline Std.err. & \multicolumn{2}{|c|}{0.0021} & \multicolumn{2}{|c|}{0.0024} & \multicolumn{2}{|c|}{0.0024} & \multicolumn{2}{|c|}{0.0023} \\
\hline$v^{(i)}$ & & & \multicolumn{2}{|c|}{$6.0583 * * *$} & $6.0789 * * *$ & $6.0134 * * *$ & \multicolumn{2}{|c|}{$1.3234 * * *$} \\
\hline Std.err. & & & \multicolumn{2}{|c|}{0.9544} & 1.6734 & 1.4119 & \multicolumn{2}{|c|}{0.0598} \\
\hline $\log (\mathrm{L})$ & \multicolumn{2}{|c|}{-2050.44} & \multicolumn{2}{|c|}{-2013.2} & \multicolumn{2}{|c|}{-2017.57} & \multicolumn{2}{|c|}{-2013.22} \\
\hline$\sigma^{2}$ & 1.3564 & 3.433 & 1.3059 & 3.2417 & 1.3059 & 3.2492 & 3.2087 & 1.3 \\
\hline$\pi$ & 0.5103 & 0.4897 & 0.4722 & 0.5278 & 0.4722 & 0.5278 & 0.5278 & 0.4722 \\
\hline Persistence & 0.9899 & 0.3654 & 0.9915 & 0.5014 & 0.9915 & 0.5029 & 0.4259 & 0.9903 \\
\hline \multirow[t]{2}{*}{ LBQ(22) } & \multicolumn{2}{|c|}{34.9963} & 34.9 & 963 & 34.9 & 963 & 34. & 963 \\
\hline & $(0.0$ & 388) & $(0.03$ & 388) & $(0.0$ & 88) & $(0.0$ & 388) \\
\hline $\mathrm{LBQ}^{2}(22)$ & 178 & 7254 & 178.6 & 6977 & 178. & 7734 & 178. & 7132 \\
\hline & $(0.0$ & 000) & $(0.00$ & 000) & $(0.0$ & $00)$ & $(0.0$ & $000)$ \\
\hline
\end{tabular}

*** and ** refer the significance at $99 \%$ and $95 \%$ confidence level respectively, LBQ(22) is Ljung-Box test of innovation at lag 22 , LBQ ${ }^{2}(22)$ is Ljung-Box test of squared innovation at lag 22 and P-value for LBQ test in parentheses. Std.err is standard error. 
Table 5. In-sample evaluation results.

\begin{tabular}{|c|c|c|c|c|c|c|c|c|c|c|c|c|c|c|c|c|c|c|c|c|}
\hline Models & $\mathrm{N}$ & PERS & AIC & $\mathrm{R}$ & SBIC & $\mathrm{R}$ & LOGL & $\mathrm{R}$ & MSE1 & $\mathrm{R}$ & MSE2 & $\mathrm{R}$ & QLIKE & $\mathrm{R}$ & MAD2 & $\mathrm{R}$ & MAD1 & $\mathrm{R}$ & HMSE & $\mathrm{R}$ \\
\hline GARCH-N & 4 & 0.9724 & 3.5089 & 9 & 3.5260 & 9 & -2087.32 & 10 & 1.3811 & 12 & 50.1151 & 8 & 1.6646 & 7 & 8.4461 & 13 & 2.7378 & 12 & 0.8701 & 12 \\
\hline GARCH-t & 5 & 0.9654 & 3.4210 & 4 & 3.4423 & 1 & -2033.89 & 5 & 1.3298 & 8 & 48.2319 & 2 & 1.6659 & 10 & 8.4433 & 12 & 2.6606 & 6 & 0.8611 & 11 \\
\hline GARCH-GED & 5 & 0.9672 & 3.4282 & 6 & 3.4496 & 5 & -2038.22 & 7 & 1.3337 & 10 & 48.5005 & 6 & 1.6652 & 9 & 8.3971 & 9 & 2.6654 & 7 & 0.8589 & 9 \\
\hline EGARCH-N & 5 & 0.0459 & 3.9850 & 13 & 4.0063 & 13 & -2370.03 & 13 & 1.1555 & 1 & 48.1433 & 1 & 2.1364 & 12 & 7.1405 & 3 & 2.1949 & 3 & 0.7389 & 3 \\
\hline EGARCH-t & 6 & 0.0491 & 3.6349 & 11 & 3.6605 & 11 & -2160.38 & 11 & 1.1584 & 2 & 48.3600 & 5 & 2.1317 & 11 & 7.1359 & 2 & 2.1939 & 1 & 0.7384 & 1 \\
\hline EGARCH-GED & 6 & 0.0461 & 3.6764 & 12 & 3.7020 & 12 & -2185.16 & 12 & 1.1608 & 3 & 48.3539 & 3 & 2.1563 & 13 & 7.1297 & 1 & 2.1945 & 2 & 0.7388 & 2 \\
\hline GJR-GARCH-N & 5 & 0.9741 & 3.5095 & 10 & 3.5309 & 10 & -2086.68 & 9 & 1.3896 & 13 & 50.5501 & 9 & 1.6635 & 5 & 8.4406 & 11 & 2.7520 & 13 & 0.8706 & 13 \\
\hline GJR-GARCH-t & 6 & 0.9682 & 3.4222 & 5 & 3.4478 & 3 & -2033.63 & 4 & 1.3328 & 9 & 48.3546 & 4 & 1.6647 & 8 & 8.4319 & 10 & 2.6658 & 8 & 0.8604 & 10 \\
\hline GJR-GARCH-GED & 6 & 0.9696 & 3.4294 & 7 & 3.4550 & 7 & -2037.92 & 6 & 1.3381 & 11 & 48.6682 & 7 & 1.6641 & 6 & 8.3906 & 8 & 2.6733 & 9 & 0.8588 & 8 \\
\hline MRS-GARCH-N & 10 & 0.9911 & 3.4571 & 8 & 3.4998 & 8 & -2050.44 & 8 & 1.3002 & 4 & 51.2119 & 10 & 1.6149 & 2 & 8.2523 & 5 & 2.6546 & 4 & 0.8427 & 5 \\
\hline MRS-GARCH-2t & 12 & 0.9920 & 3.3980 & 2 & 3.4492 & 4 & -2013.2 & 1 & 1.3254 & 6 & 55.5689 & 12 & 1.6152 & 3 & 8.2603 & 7 & 2.6913 & 10 & 0.8465 & 7 \\
\hline MRS-GARCH-t & 11 & 0.9910 & 3.4036 & 3 & 3.4506 & 6 & -2017.57 & 3 & 1.3047 & 5 & 52.8737 & 11 & 1.6148 & 1 & 8.2246 & 4 & 2.6602 & 5 & 0.8413 & 4 \\
\hline MRS-GARCH-GED & 11 & 0.9921 & 3.3963 & 1 & 3.4433 & 2 & -2013.22 & 2 & 1.3268 & 7 & 56.0621 & 13 & 1.6157 & 4 & 8.2578 & 6 & 2.6917 & 11 & 0.8461 & 6 \\
\hline
\end{tabular}

$\mathrm{N}=$ Number of Parameters, PERS = Persistence, $\mathrm{R}=$ Rank.

the results of goodness-of-fit statistics and loss functions ${ }^{7}$ for all volatility models are presented. According to AIC, MRS-GARCH-GED is the best. GARCH-t is the best in SBIC, MRS-GARCH-2t is the best in LOGL, EGARCH $-\mathrm{N}$ is the best in MSE1 and MSE2. MRS-GARCH-t is the best in QLIKE. EGARCH-GED is the best in MAD2 and EGARCH-t is the best in MAD1 and HMSE. We found that different models were suitable for various loss functions.

\section{Forecasting Volatility in Out-of-Sample}

In this section, we investigate the ability of MRS-GARCH and GARCH type models to forecast volatility of Gold prices from out-of-sample.

In Table 6, we present the result of loss function of out-of-sample with forecasting volatility for one day ahead, and we found the EGARCH and MRS-GARCH models perform best.

$$
\begin{aligned}
& { }^{7} \text { Loss functions: } \\
& M S E_{1}=\frac{1}{n} \sum_{t=1}^{n}\left(\sigma_{t+K}-\sqrt{h_{t, K}}\right)^{2}, M S E_{2}=\frac{1}{n} \sum_{t=1}^{n}\left(\sigma_{t+K}^{2}-h_{t, K}\right)^{2}, \\
& \text { QLIKE }=\frac{1}{n} \sum_{t=1}^{n}\left(\ln \left(h_{t, K}\right)-\frac{\sigma_{t+K}^{2}}{h_{t, K}}\right), \\
& M A D_{1}=\frac{1}{n} \sum_{t=1}^{n}\left|\sigma_{t+K}-\sqrt{h_{t, K}}\right|, M A D_{2}=\frac{1}{n} \sum_{t=1}^{n}\left|\sigma_{t+K}^{2}-h_{t, K}\right|, \\
& H M S E=\frac{1}{n} \sum_{t=1}^{n}\left(\frac{\sigma_{t+K}^{2}}{h_{t, K}}-1\right)^{2}
\end{aligned}
$$

\section{Trading Future Contract with Forecast Volatility and Forecast Price}

The aim of this study is to evaluate the profitability of applying different models to the volatility of gold prices. We assumed the market is a perfect market and the positions in our strategy are not longer than one day as described below.

We applied the Bollinger band indicator and we used samples of 21 days from 1 to 30 August 2011 (We trade one contract in GF10Q11 series is future contract in gold price with maturity date at August 2011) to trade in one contract with day by day and we did not include settlement, return do not include cost price i.e. margin, fee charged. The net daily rate of return for long position is computed as follows:

$$
R_{t+1}=C_{t+1}-\left(O_{t+1}-m \cdot \sqrt{h_{t+1}}\right)
$$

where $R_{t+1}, C_{t+1}, O_{t+1}$ are the return, close, open price, $h_{t+1}$ is forecasting volatility at next day $(t+1)$ and $m \in \mathbb{Z}^{+}$is constants.

The net daily rate of return on close position is computed as follows:

$$
R_{t+1}=\left(O_{t+1}+m \cdot \sqrt{h_{t+1}}\right)-C_{t+1}
$$

Table 7 shows that the cumulative of return with Markov Regime Switching the GARCH-N model and the GJR-N model give cumulative of return more than the 
Table 6. Result loss function of out-of-sample with forecasting volatility for one day ahead.

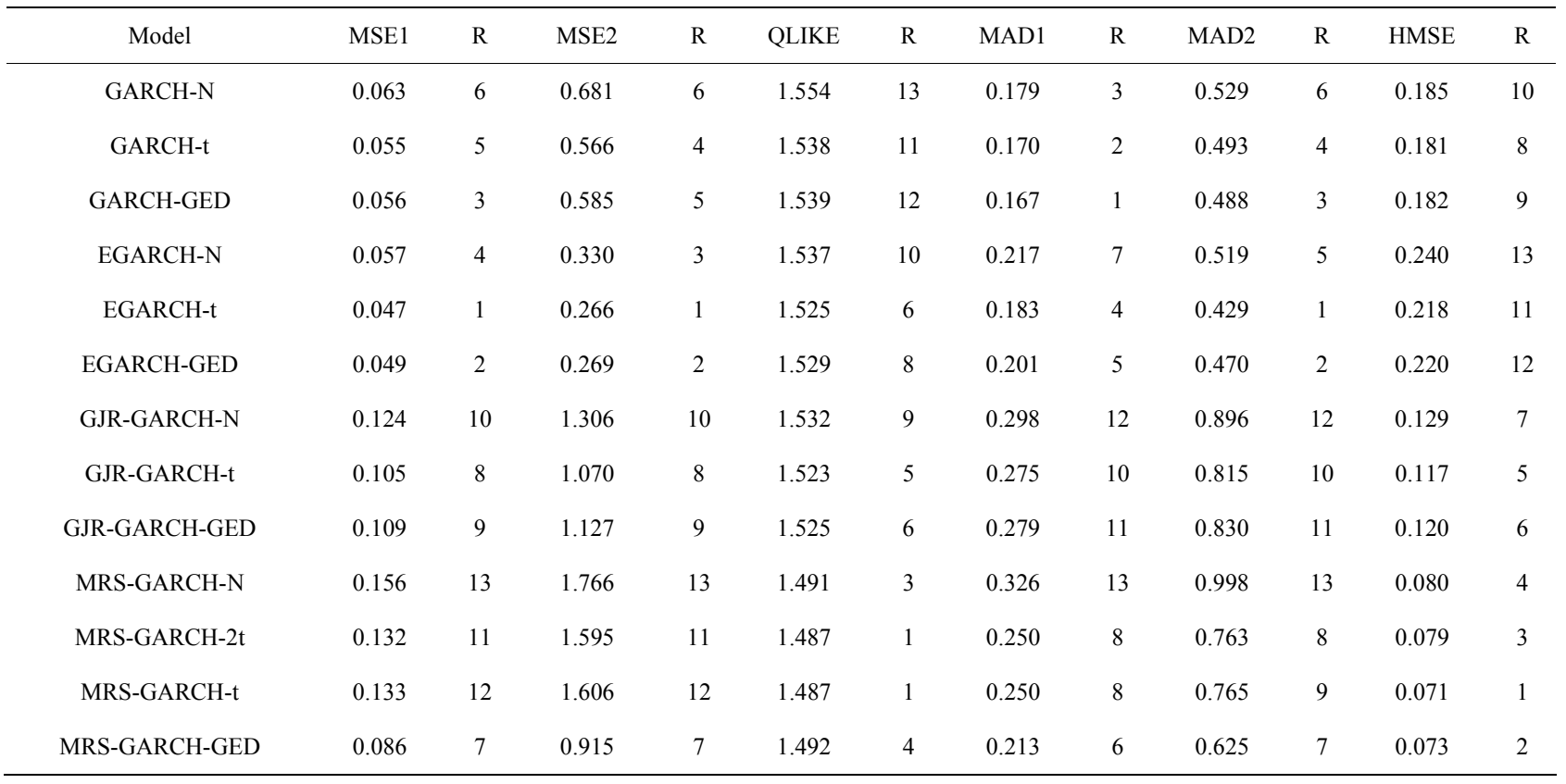

Table 7. Cumulative Return of trading future contract of gold price with $\boldsymbol{m}=30$ between 1 to 30 August 2011 .

\begin{tabular}{|c|c|c|c|c|c|c|c|c|c|c|c|c|c|}
\hline \multirow{2}{*}{$\begin{array}{l}\text { Date with } \\
\text { Trading. }\end{array}$} & \multicolumn{3}{|c|}{ GARCH } & \multicolumn{3}{|c|}{ EGARCH } & \multicolumn{3}{|c|}{ GJR } & \multicolumn{4}{|c|}{ MRS-GARCH } \\
\hline & $\mathrm{N}$ & $\mathrm{t}$ & GED & $\mathrm{N}$ & $\mathrm{t}$ & GED & $\mathrm{N}$ & $\mathrm{t}$ & GED & $\mathrm{N}$ & $\mathrm{t}$ & $2 \mathrm{t}$ & GED \\
\hline $1 / 8 / 2011$ & -40.0 & -40.0 & -40.0 & -40.0 & -40.0 & -40.0 & -40.0 & -40.0 & -40.0 & -50.0 & -50.0 & -50.0 & -50.0 \\
\hline $2 / 8 / 2011$ & -100.0 & -90.0 & -90.0 & -80.0 & -90.0 & -90.0 & -90.0 & -90.0 & -90.0 & -110.0 & -110.0 & -110.0 & -110.0 \\
\hline $3 / 8 / 2011$ & 620.0 & 630.0 & 630.0 & 630.0 & 630.0 & 620.0 & 630.0 & 630.0 & 630.0 & 600.0 & 600.0 & 600.0 & 600.0 \\
\hline 4/8/2011 & 700.0 & 710.0 & 710.0 & 710.0 & 710.0 & 690.0 & 710.0 & 710.0 & 710.0 & 670.0 & 670.0 & 670.0 & 680.0 \\
\hline $5 / 8 / 2011$ & 740.0 & 750.0 & 750.0 & 750.0 & 750.0 & 730.0 & 750.0 & 750.0 & 750.0 & 700.0 & 700.0 & 700.0 & 710.0 \\
\hline $8 / 8 / 2011$ & 1470.0 & 1490.0 & 1480.0 & 1490.0 & 1490.0 & 1470.0 & 1500.0 & 1500.0 & 1500.0 & 1420.0 & 1420.0 & 1420.0 & 1430.0 \\
\hline $9 / 8 / 2011$ & 2530.0 & 2550.0 & 2540.0 & 2530.0 & 2530.0 & 2510.0 & 2560.0 & 2560.0 & 2560.0 & 2480.0 & 2460.0 & 2460.0 & 2480.0 \\
\hline $10 / 8 / 2011$ & 2510.0 & 2530.0 & 2520.0 & 2520.0 & 2500.0 & 2480.0 & 2560.0 & 2560.0 & 2560.0 & 2460.0 & 2430.0 & 2430.0 & 2460.0 \\
\hline $11 / 8 / 2011$ & 2190.0 & 2210.0 & 2200.0 & 2180.0 & 2170.0 & 2150.0 & 2260.0 & 2260.0 & 2260.0 & 2180.0 & 2120.0 & 2120.0 & 2160.0 \\
\hline $15 / 8 / 2011$ & 1750.0 & 1770.0 & 1750.0 & 1710.0 & 1700.0 & 1680.0 & 1830.0 & 1830.0 & 1830.0 & 1760.0 & 1670.0 & 1670.0 & 1710.0 \\
\hline $16 / 8 / 2011$ & 1440.0 & 1460.0 & 1440.0 & 1370.0 & 1360.0 & 1340.0 & 1520.0 & 1520.0 & 1520.0 & 1460.0 & 1350.0 & 1350.0 & 1400.0 \\
\hline $17 / 8 / 2011$ & 1670.0 & 1690.0 & 1660.0 & 1570.0 & 1560.0 & 1540.0 & 1750.0 & 1750.0 & 1750.0 & 1700.0 & 1570.0 & 1570.0 & 1620.0 \\
\hline $18 / 8 / 2011$ & 1770.0 & 1790.0 & 1760.0 & 1640.0 & 1640.0 & 1610.0 & 1860.0 & 1850.0 & 1850.0 & 1820.0 & 1670.0 & 1670.0 & 1720.0 \\
\hline $19 / 8 / 2011$ & 2670.0 & 2690.0 & 2660.0 & 2520.0 & 2520.0 & 2490.0 & 2770.0 & 2760.0 & 2760.0 & 2730.0 & 2570.0 & 2570.0 & 2620.0 \\
\hline $22 / 8 / 2011$ & 3510.0 & 3530.0 & 3500.0 & 3340.0 & 3360.0 & 3310.0 & 3620.0 & 3610.0 & 3610.0 & 3590.0 & 3410.0 & 3410.0 & 3460.0 \\
\hline $23 / 8 / 2011$ & 3840.0 & 3850.0 & 3820.0 & 3650.0 & 3670.0 & 3610.0 & 3960.0 & 3950.0 & 3950.0 & 3930.0 & 3740.0 & 3740.0 & 3780.0 \\
\hline $24 / 8 / 2011$ & 2870.0 & 2880.0 & 2850.0 & 2710.0 & 2680.0 & 2630.0 & 3030.0 & 3020.0 & 3020.0 & 3000.0 & 2800.0 & 2800.0 & 2830.0 \\
\hline $25 / 8 / 2011$ & 5220.0 & 5230.0 & 5200.0 & 5040.0 & 5000.0 & 4950.0 & 5430.0 & 5410.0 & 5420.0 & 5420.0 & 5220.0 & 5220.0 & 5220.0 \\
\hline $26 / 8 / 2011$ & 4390.0 & 4400.0 & 4370.0 & 4120.0 & 4080.0 & 4050.0 & 4590.0 & 4570.0 & 4580.0 & 4640.0 & 4450.0 & 4450.0 & 4410.0 \\
\hline $29 / 8 / 2011$ & 5240.0 & 5240.0 & 5210.0 & 4900.0 & 4870.0 & 4820.0 & 5450.0 & 5420.0 & 5430.0 & 5460.0 & 5270.0 & 5270.0 & 5220.0 \\
\hline $30 / 8 / 2011$ & 4920.0 & 4920.0 & 4890.0 & 4520.0 & 4470.0 & 4420.0 & 5150.0 & 5110.0 & 5120.0 & 5150.0 & 4960.0 & 4960.0 & 4900.0 \\
\hline
\end{tabular}


other models when we use $m=30$.

\section{Conclusions}

In this paper, we forecast volatility of gold prices using Markov Regime Switching GARCH (MRS-GARCH) models. These models allow volatility to have different dynamics according to unobserved regime variables.

The main purpose of this paper is to find out whether MRS-GARCH models are an improvement on the GARCH type models which include GARCH $(1,1)$, EGARCH $(1,1)$ and GJR-GARCH $(1,1)$ in terms of modeling and forecasting gold price closed price volatility. We compare MRS-GARCH $(1,1)$ models with GARCH $(1,1)$, EGARCH $(1,1)$, GJR-GARCH $(1,1)$ models. All models are estimated under three distributional assumptions which are Nor- mal, Student-t and GED. Moreover, Student-t distribution which takes different degrees of freedom in each regime is considered for MRS-GARCH models.

We first analyze in-sample performance of various volatility models to determine the best form of the volatility model over the period 4/01/2007 through 30/08/2011. As expected, volatility is not constant over time and exhibits volatility clustering showing large changes in the price of an asset often followed by large changes, and small changes often followed by small changes.

Descriptive statistics of return series are represented by returns with fatter tails. The Augmented DickeyFuller test indicates gold price log returns are stationary. Serial correlation in the gold price confirms it is nonstationary but serial log returns of gold price are stationary. Serial correlation in the squared returns suggests conditional heteroskedasticity. This empirical part adopts GARCH type and MRS-GARCH models to estimate the volatility of the gold price. In order to account for fat tailed features of financial returns, we consider three different distributions for the innovations. Almost all parameter estimates in GARCH type models are highly significant at $1 \%$. Most parameter estimates in MRS-GARCH are significantly different from zero at least at $95 \%$ confidence level. However, the results of goodness-of-fit statistics and loss functions for all volatility models show different results.

The trading details we have used describe forecasts of closed price of gold price between 1/08/2011-30/08/2011 and trading in gold future contract (GF10Q11). We found the cumulative returns with the Markov Regime Switching GARCH-N (MRS-GARCH-N) model and the GJR-N model give us higher cumulative returns than the other models when we use $m=30$.

For further study, three or four volatility regimes setting can be considered rather than two-volatility regimes. Also, using Markov Regime Switching with other volatility models e.g. EGARCH, GJR. In addition, the per- formance of MRS-GARCH models can be hedged in future for long and short positions.

\section{Acknowledgements}

This research is (partially) supported by the Thailand research fund BRG.

\section{REFERENCES}

[1] A. Mehmet, "Analysis of Turkish Financial Market with Markov Regime Switching Volatility Models," The Middle East Technical University, Ankara, 2008.

[2] R. Engle, "Autoregressive Conditional Heteroscedasticity with Estimates of the Variance of United Kingdom Inflation," Econometrica, Vol. 50, No. 4, 1982, pp. 987-1008. doi: $10.2307 / 1912773$

[3] T. Bollerslev, "Generalized Autoregressive Conditional Heteroscedasticity," Journal of Econometrics, Vol. 31, No. 3, 1986, pp. 307-327. doi:10.1016/0304-4076(86)90063-1

[4] D. B. Nelson, "Conditional Heteroskedasticity in Asset Returns: A New Approach," Econometrica, Vol. 59, No. 2, 1991, pp. 347-370. doi:10.2307/2938260

[5] L. R. Glosten, R. Jagannathan and D. Runkle, "On the Relation between the Expected Value and the Nominal Excess Return on Financials," Journal of Finance, Vol. 48, No. 5, 1993, pp. 1779-1801. doi:10.2307/2329067

[6] J. D. Haminton and R. Susmel, "Autoregressive Conditional Heteroskedasticity and Change in Regime," Journal of Econometrics, Vol. 64, No. 1-2, 1994, pp. 307-333. doi:10.1016/0304-4076(94)90067-1

[7] Z. F. Guo and L. Cao, "A Smooth Transition GARCH Model with Asymmetric Transition Phases," Proceedings of International Conference of Financial Engineering, London, 6-8 July 2011.

http://www.iaeng.org/publication/WCE2011/WCE2011_pp 439-441.pdf

[8] Z. F. Guo and L. Cao, "An Asymmetric Smooth Transition GARCH Model," IAENG Journals, 2011. http://www.iaeng.org/IJAM/issues_v41/issue_4/IJAM_41 4_10.pdf

[9] J. Marcucci, "Forecasting Financial Market Volatility with Regime-Switching GARCH Model," Working Paper, University of California, San Diego, 2005.

[10] T. Edel and M. Brian, "APGARCH Investigation of the Main Influences on the Gold Price," University of Dublin, Dublin, 2005.

[11] S. Gray, "Modeling the Conditional Distribution of Interest Rates as a Regime-Switching Process," Journal of Financial Economics, Vol. 42, No. 1, 1996, pp. 27-62. doi:10.1016/0304-405X(96)00875-6

[12] F. Klaanssen, "Improving GARCH Volatility Forecasts with Regime-Switching GARCH," Empirical Economics, Vol. 27, No. 2, 2002, pp. 363-394. doi: $10.1007 / \mathrm{s} 001810100100$

[13] C. J. Kimand and C. R. Nelson, "State-Space Models with Regime Switching: Classical and Gibbs-Sampling Approa- 
ches with Applications," MIT Press, Cambridge, 1999.

[14] J. D. Hamilton, "A New Approach to the Economic Analysis of Nonstationary Time Series and the Business Cycle," Econometrica, Vol. 57, No. 2, 1989, pp. 357-384.

$$
\text { doi: } 10.2307 / 1912559
$$

[15] J. D. Hamilton, "Analysis of Time Series Subject to Change in Regime," Journal of Econometrics, Vol. 45, No. 1-2, 1990, pp. 39-70. doi:10.1016/0304-4076(90)90093-9 